\section{RMD Open}

Rheumatic \&

Musculoskeletal Diseases

\title{
Normative ultrasound references for the paediatric wrist; dorsal soft tissues
}

\author{
Karen Rosendahl, ${ }^{1,2}$ Ingvild Sævold Bruserud, ${ }^{3}$ Ninnie Oehme, ${ }^{3}$ \\ Pétur Benedikt Júlíusson, ${ }^{3,4}$ Laura Tanturri de Horatio, ${ }^{5}$ Lil-Sofie Ording Müller, ${ }^{6}$ \\ Silvia Magni-Manzoni ${ }^{7}$
}

To cite: Rosendahl K, Bruserud IS, Oehme N, et al. Normative ultrasound references for the paediatric wrist; dorsal soft tissues. RMD Open Published Online First: [please include Day Month Year]. doi:10.1136/ rmdopen-2017-000642

\section{- Prepublication history for this paper is available online. To view these files, please visit the journal online (http://dx.doi. org/10.1136/rmdopen-2017- 000642)}

Received 28 December 2017 Revised 12 February 2018 Accepted 26 February 2018

Check for updates

1Department of Radiology, Haukeland University Hospital, Bergen, Norway

${ }^{2}$ Department of Clinical Medicine, K1, University of Bergen, Bergen, Norway ${ }^{3}$ Department of Clinical Medicine, K2, University of Bergen, Bergen, Norway ${ }^{4}$ Department of Pediatrics, Haukeland University Hospital, Bergen, Norway

${ }^{5}$ Department of Radiology, Bambino Gesù Children's Hospital, Rome, Italy ${ }^{6}$ Department of Radiology and Intervention, Oslo University Hospital, Oslo, Norway ${ }^{7}$ Pediatric Rheumatology, Bambino Gesù Children's Hospital, Rome, Italy

\section{Correspondence to} Dr Karen Rosendahl; karen.rosendahl@helse-bergen. no

\section{ABSTRACT}

Objective To report novel ultrasound (US) references for the healthy paediatric wrist.

Methods Healthy children and adolescents had an US examination including Doppler, of the right wrist, using a mid-sagittal image through the radiocarpal (RC)/midcarpal (MC) joints. These features were noted: appearances and depth of the recess, with an additional measurement in the flexed position and number of Doppler signals within the recess in close proximity to the joint. In a second, blinded session, all images were reassessed by the same observer. Results In total, 116 subjects (59 girls) aged 6-16 years (mean 10 years and 11 months) were included. The RC recess was visible in 71, of which 60 were non-bulging and 11 were bulging. In flexion, the thickness decreased in $60(84.5 \%)$, suggestive of joint fluid. Of the 54 visible MC recesses, $45(83.3 \%)$ thinned in flexion. The mean depths of the $\mathrm{RC}$ and $\mathrm{MC}$ recesses were $0.4 \mathrm{~mm}$ (SD 0.5, range $0-2.9$ ) and $0.5 \mathrm{~mm}$ (SD 0.6, range 0-2.4), respectively, with no differences according to sex, but with increasing depths by age. For the RC joints, at least one Doppler signal was seen in the recess in $9 / 116$ joints $(7.8 \%)$, whereas this was true for $3.5 \%$ of the $\mathrm{MC}$ recesses. There were no statistically significant association between the depth of the $\mathrm{RC}$ or $\mathrm{MC}$ recesses and number of hand active sport activities ( $\mathrm{P}=0.733$ and $\mathrm{P}=0.091$, respectively). Conclusion The appearances of the dorsal RC and MC recesses in healthy children may mimic pathology. Hence, findings should be interpreted carefully.

\section{INTRODUCTION}

Imaging in general, and ultrasound (US) in particular, has become exceedingly important in the diagnosis and follow-up of joint disease, allowing for personalised medicine. Correct interpretation of the findings warrants a detailed knowledge of the normal appearances and of the disease processes. Imaging children represents a particular challenge as normal appearances change by age, thus mimicking diseases such as juvenile idiopathic arthritis (JIA), characterised by chronic synovial inflammation with potential risk of developing progressive joint destruction and serious functional disability. ${ }^{1}$

\section{Key messages}

What is already known about this subject?

- To our knowledge, this is the first study presenting normal ultrasound (US) appearances of the wrist in children.

What does this study add?

- On US, the dorsal recess of the radiocarpal (RC) and midcarpal (MC) joints is visible in more than half of healthy children and is perceived as bulging in 1 out of $10 \mathrm{RC}$ recesses and in 1 out of $5 \mathrm{MC}$ recesses.

- At least one vessel can be found in around $8 \%$ of the $\mathrm{RC}$ recesses and in $3.5 \%$ of the $\mathrm{MC}$ recesses.

How might this impact on clinical practice?

- The above findings can mimic pathology.

The synovium is the soft tissue lining the spaces of the diarthrodial joints except for the cartilage, tendon sheaths and bursae. It consists of a continuous surface layer of cells, the intima and an underlying layer, the synovial sublining. ${ }^{34}$ The intima consists of macrophages and fibroblasts and is typically $20-40 \mu \mathrm{m}$ thick, whereas the sublining includes blood and lymphatic vessels and can measure up to $5 \mathrm{~mm}$ in thickness. ${ }^{3}$ Histologically, there are three different types, namely a fibrous, an areolar with multiple layers of lining cells for stretching and folding and an adipose. To date, little is known about the type and imaging appearances of normal synovium in the wrist. ${ }^{3}$

On US, the synovium appears as a solid layer with varying echogenicity and thickness according to type and joint. Normal, child-specific US references have been published for the hip joint ${ }^{56}$ and, more recently, for the shoulder. ${ }^{7}$ However, data for other joints are sparse although the Paediatric Group of the Outcome Measures in Rheumatology (OMERACT) US Task Force addressed the issue in a few papers. ${ }^{89}$ Further, despite 
the existence of multiple studies that used US to assess synovitis in JIA, ${ }^{10}$ there are no well-accepted US protocol recommendations for assessing joints of children with JIA. ${ }^{11}$

Normal joint fluid is seen as a dark zone which is displaceable by the transducer. Normal references on the distribution within the wrist joints exist for MRI, but not for US. ${ }^{12}$

The aim of the present study was to establish references for synovial thickness as defined by the thickness of the dorsal recesses of the radiocarpal (RC) and midcarpal (MC) joints, presence of joint fluid and presence of vessels as shown on Doppler, in children, aged $6-15$ years, to better differentiate between normality and pathology.

\section{MATERIAL AND METHODS}

The current study is part of the Bergen Growth Studies 2 (BGS2), aiming to establish novel references for pubertal development. Children invited for a substudy of BGS2 had an additional US of the right wrist. This particular substudy took place in a combined primary/secondary school (1st to 10th grade, age 6-16 years) in Bergen and at the Haukeland University Hospital. The invitations were given by a visit to each of 10 different classes in the selected school, or via the coach of a local football club, for investigation at the hospital. The cohort was recruited using stratified (age and sex) random sampling to provide a balanced dataset. All participants were rewarded with a cinema ticket. Prior to the US examination, the children were asked about handedness, whether or not they had sustained recent injuries to the right wrist, for example, within the previous 3 weeks, and whether or not they did organised sports/training, and if yes, the type and number of training sessions per week. The type of sports was subgrouped according to the perceived degree of hand involvement, at a scale from 0 (no hand involvement) to 4 ( 4 or more hand active training sessions per week). The examiner (KR) did a fast, clinical assessment with regard to joint swelling. Those who had sustained a recent injury to the wrist and those with swelling of one or more of the hand joints were excluded.

One examiner with 25 years of experience in paediatric musculoskeletal imaging (KR) performed all the US examinations, using a state-of-the art US machine (Toshiba Aplio 500), with a linear, $5-14 \mathrm{mHz}$ transducer. With the child seated and the right hand placed on a table in neutral, flat position, a mid-sagittal image through the RC/MC joints was obtained (figure 1), followed by a colour Doppler examination (small field of view, low-flow setting $(3.5 \mathrm{~cm} / \mathrm{s}))$. In cases of a visible dorsal recess (representing a double layer of synovium) extending from either of the two joints, additional mid-sagittal images with the wrist flexed (around $30-40^{\circ}$ ) were performed to examine whether the structure presumed to represent a recess decreased in depth or not, for example, representing at least some fluid rather than
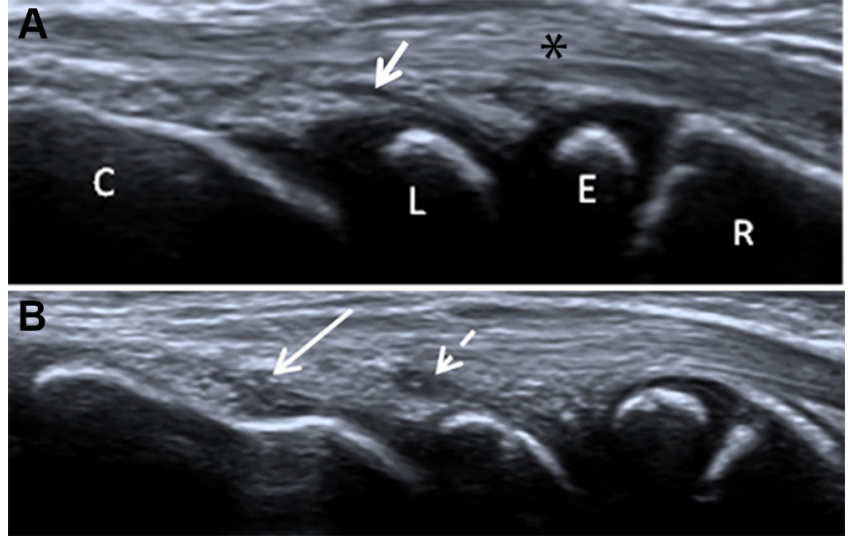

Figure 1 A mid-sagittal view through the dorsum of the wrist in (A) a 7-year-old, healthy girl. The $R C$ recess is visible (score 1, short arrow), whereas the MC recess does not show (score 0 ) and in (B) a 9-year-old, healthy boy showing bulging MC (score 2, long arrow) and RC (score 2, stippled arrow) recesses. *4th compartment of the extensor tendons. C, capitate; E, distal-radial epiphysis; L, lunatum; MC, midcarpal; $\mathrm{R}$, distal radius; $\mathrm{RC}$, radiocarpal.

synovium only. A visible recess was defined as a sharply delineated, hypoechoic pouch extending from the joint, in a distal direction (figure 1). The following features were noted: (1) appearances of the recess (scored as $0=$ not visible, $1=$ =visible but not bulging, $2=$ bulging), (2) recess thickness in mm (measured at its maximum depth in neutral (figure 2), with an additional measurement in the flexed position as appropriate), (3) Doppler signals within the recess (number) and (4) Doppler signals in close proximity to the joint. In a second session after 6 weeks, using a masked design, the thickness of the recesses (in $\mathrm{mm}$ ) and its appearances on a 0-2 scale was reassessed from the images by the same observer (KR). Data (textual and numerical) were registered and stored in a common database (SPSS), whereas images were stored on an external hard disk (anonymous fashion, for later remeasurements). The study was approved by

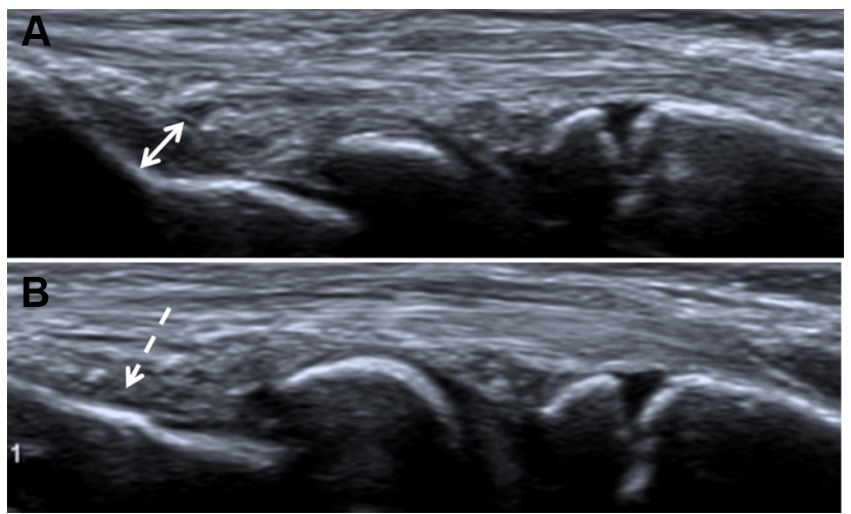

Figure 2 Mid-sagittal US images in an 11-year-old boy with the wrist in $(A)$ neutral position showing a bulging $M C$ recess (measured from the surface of the capitate to the junction between hypoechoic and hyperechoic tissue, double arrow) and in (B) flexed position showing a reduced depth (stippled arrow). MC, midcarpal; US, ultrasound. 
Table 1 Ultrasound scoring of the dorsal RC and MC synovial recesses in 116 healthy children (59 women) aged 6-16 years

\begin{tabular}{lllll}
\hline & $\begin{array}{l}\text { Score 0 } \\
\text { (not visible) }\end{array}$ & $\begin{array}{l}\text { Score 1 } \\
\text { (visible, not bulging) }\end{array}$ & $\begin{array}{l}\text { Score 2 } \\
\text { (visible, } \\
\text { bulging) }\end{array}$ & Total \\
\hline $\mathrm{RC}$ recess & $45(38.8 \%)$ & $60(51.7 \%)$ & $11(9.5 \%)$ & 116 \\
$\mathrm{MC}$ recess & $62(53.5 \%)$ & $34(29.3 \%)$ & $20(17.2 \%)$ & 116 \\
\hline
\end{tabular}

$\mathrm{MC}$, midcarpal; RC, radiocarpal.

the regional ethics committee (REK-West 2015/128). Written consent was received from all participant and/ or their caretakers.

\section{Statistical analysis}

Differences between sexes for categorical scores of the synovium and for mean thickness of the synovial recesses were examined using a $\mathrm{X}^{2}$ test and independent samples $\mathrm{t}$-test, respectively. Differences in the appearances of the $\mathrm{RC}$ and MC recesses (subjective grading on a $0-2$ scale) by age group (group $1=6-7$ years, group $2=8-9$ years, group 3=10-11 years, group $4=12-13$ years and group $5=14-15$ years) were examined using a $X^{2}$ test (linear-bylinear association), whereas differences in the depth of the recesses were examined by using a one-way between group analysis of variance (ANOVA).

Intraobserver agreement for the grading of the recess in each of the two joints was determined using simple Cohen's kappa. A kappa score of $<0.2$ is considered poor, $0.21-0.40$ fair, $0.41-0.60$ moderate, $0.61-0.80$ good and $0.81-1.00$ very good. Repeatability of continuous variables was analysed by establishing $95 \%$ limits of agreement (termed repeatability coefficient, when used for repeat measurements) as per Bland and Altman. Bland-Altman plots are generally interpreted informally, and a clinically acceptable agreement was set at $\leq 0.15(15 \%)$. A significance level of 0.05 was decided a priori, and all the reported $\mathrm{P}$ values are two tailed. Statistical analysis was performed using Predictive Analytics Software V.24 (SPSS 24).

\section{RESULTS}

In total, 116 children (59 girls) aged $6-16$ years (mean 10 years and 11 months, SD 3.0 years) were included. Out of the 116 children ( 7 women), 21 did no sport activities, whereas 36 (16 women) did 1-2 training sessions per week and 69 (12 women) did 3 or more weekly sessions. When subgrouping the type of sport activity based on the degree of hand involvement, using a $0-4$ scale, 12/59 women and 26/57 men had a score of 1-4. Eleven (9.5\%) children (6 girls) were left-handed. None reported on wrist pain.

For subjective scoring of the $\mathrm{RC}$ and $\mathrm{MC}$ recesses, no differences were seen according to sex, hence the results were merged ( $\mathrm{X}^{2}$ tests, $\mathrm{P}=0.448$ and 0.447 , respectively, for the $\mathrm{RC}$ and the $\mathrm{MC}$ recesses) (table 1 ).

In 45 out of the $116 \mathrm{RC}$ joints (38.8\%), no recess was seen (score 0 ), whereas a small recess without bulging (score 1) was seen in 60 wrists $(51.7 \%)$ and a bulging recess (score 2) was seen in 11 (9.5\%) (table 1) (figure 1).

The mean depth of the $\mathrm{RC}$ recess was $0.4 \mathrm{~mm}$ for girls (SD $0.4 \mathrm{~mm})$ and $0.4 \mathrm{~mm}$ for boys $(\mathrm{SD} 0.6 \mathrm{~mm})(\mathrm{P}=0.917$, independent samples t-test). For the $\mathrm{MC}$ recess, the values were $0.4 \mathrm{~mm}$ (SD $0.5 \mathrm{~mm}$ ) and $0.5 \mathrm{~mm}$ (SD $0.7 \mathrm{~mm}$ ), respectively ( $\mathrm{P}=0.558$, independent samples t-test $)$. As no statistically significant differences in mean values were found between sexes for any of the five age groups, the results were pooled. The mean thickness of both recesses increased significantly by age (table 2 ).

Overall, 71 out of the $116 \mathrm{RC}$ recesses were seen, either as non-bulging (score $1, \mathrm{n}=60$ ) or as bulging (score 2, $\mathrm{n}=11)$. Sixty out of these $(84.5 \%)$ decreased in thickness when remeasured in flexion, whereas $11(15.5 \%)$ remained unchanged (figure 2). On a 0-2 scale, 26 of 60 scored as 1 in neutral position received a score 0 in a flexed position, whereas 34 were unchanged. For those 11 judged to have a bulging recess in the neutral position, 6 were unchanged in the flexed position, whereas 5 were visible, but not bulging (score 1 ). Of the 54 visible MC recesses, $45(83.3 \%)$ decreased in depth in flexion and $9(16.7 \%)$ remained unchanged. On a $0-2$ scale, 34 out of the 54 had a score 1 , of which 28 remained unchanged, whereas 20 had a score 2 of which 9 remained unchanged in the flexed position. There were no significant differences across age groups for either of the joints (RC $\mathrm{P}=0.554$ and $\mathrm{MC} \mathrm{P}=0.398$ ).

For the RC joints, at least one Doppler signal was seen within the area of the recess in 9 of the 116 joints $(7.8 \%$, all girls), of which 8 were seen in joints with a visible but not bulging recess and 1 was seen in a bulging recess. For MC joints, Doppler signal was seen in the area of 4 recesses $(3.5 \%)$, of which 1 grade 1,1 grade 2 and 2 grade 2 (figure 3 ).

\begin{tabular}{|c|c|c|c|c|c|c|}
\hline & $\begin{array}{l}6-7 \text { years } \\
(n=20)\end{array}$ & $\begin{array}{l}8-9 \text { years } \\
(n=23)\end{array}$ & $\begin{array}{l}10-11 \text { years } \\
(n=24)\end{array}$ & $\begin{array}{l}12-13 \text { years } \\
(n=18)\end{array}$ & $\begin{array}{l}\text { 14-16years } \\
(n=31)\end{array}$ & $\begin{array}{l}\text { P value } \\
\text { (ANOVA) }\end{array}$ \\
\hline $\mathrm{RC}$ recess, mean in mm (SD) & $0.2(0.4)$ & $0.2(0.4)$ & $0.2(0.3)$ & $0.7(0.8)$ & $0.8(0.3)$ & $<0.001^{*}$ \\
\hline $\mathrm{MC}$ recess, mean in $\mathrm{mm}(\mathrm{SD})$ & $0.2(0.5)$ & $0.4(0.7)$ & $0.3(0.5)$ & $0.5(0.6)$ & $0.8(0.6)$ & 0.001 \\
\hline
\end{tabular}

*Test of homogeneity of variances $=0.01$.

ANOVA, analysis of variance; MC, midcarpal; RC, radiocarpal. 

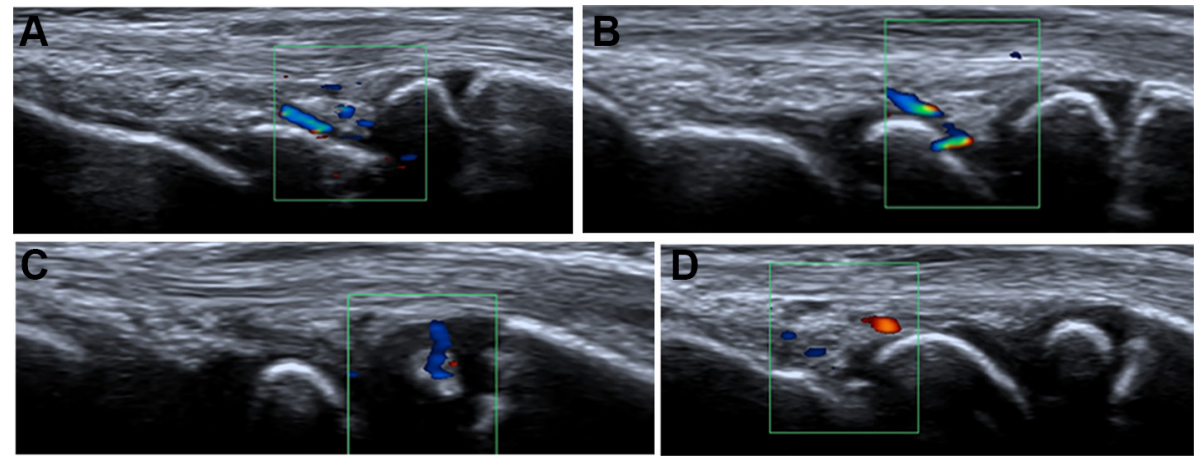

Figure 3 Mid-sagittal US images showing vessels in the RC recesses of $(A)$ a 13-year-old girl and of $(B)$ an 11-year-old boy. (C) A vessel in the radial epiphysis in a 7-year-old girl and (D) in the MC recess of a 10-year-old boy. MC, midcarpal; RC, radiocarpal; US, ultrasound.

Vessels in the distal-radial epiphysis were seen in 20 of the 116 children ( 15 women) with no differences according to age group ( $\mathrm{X}^{2}$ test, linear-by-linear association, $\mathrm{P}=0.287$ ) (table 3).

There were no statistically significant association between the depth of the RC or MC recesses and the number of hand active sport activities $(\mathrm{P}=0.733$ and $\mathrm{P}=0.091$, respectively).

For the thickness of the RC recess, the mean difference between two readings for the same observer (intraobserver variation) was $0.02 \mathrm{~mm}(95 \%$ limits of agreement $=-0.5 \mathrm{~mm}$ to $0.5 \mathrm{~mm}$ ). Corresponding measures for the MC recess were $0.02 \mathrm{~mm}$ (95\% limits of agreement $=-1.1 \mathrm{~mm}$ to $1.1 \mathrm{~mm}$ ). The intraobserver agreement for subjective scoring of the $\mathrm{RC}$ and $\mathrm{MC}$ recesses at a $0-2$ scale was very good to good, with kappa values of 0.82 (95\% CI 0.72 to 0.92 ) for the RC and 0.76 (95\% CI 0.66 to 0.86 ) for the MC joint.

\section{DISCUSSION}

We have shown, in a large cohort of healthy children, that the dorsal recess of the RC and MC joints as assessed by US on a mid-sagittal standard view with the wrist in a neutral position is visible in more than half of healthy children and is perceived as bulging in 1 out of $10 \mathrm{RC}$ recesses and in 1 out of $5 \mathrm{MC}$ recesses. One or more vessels were seen in $8 \%$ of the $\mathrm{RC}$ and $4 \%$ of the $\mathrm{MC}$ recesses. These are important observations, particularly with respect to the vessels as synovial recesses are believed to be avascular under normal circumstances. ${ }^{8}{ }^{13}$ Furthermore, nearly half of the RC recesses and $10 \%$ of the MC recesses disappeared when reimaged in the flexed wrist, consistent with the presence of joint fluid.

Although Smith, in his paper on the normal synovium, states that there is considerable variation of the typical normal synovium, ${ }^{3}$ the wide variation of synovial depth found in our cohort of healthy children is intriguing. According to Smith, the intimal lining layer typically measures up to $0.04 \mathrm{~mm}$ and the synovial sublining up to $5 \mathrm{~mm}$; however, at many sites, there is no discrete membrane, especially where the sublining consists of fat pad or fibrous tissue. ${ }^{3}$ In our cohort, the RC and MC recesses, including two layers of synovium, were measured from 0 to $3 \mathrm{~mm}$, increasing across age groups with no differences according to sex or sport activities. We have no plausible explanations for these observations. Similar findings in the metatarsophalangeal joints have been reported in a large series of healthy adults. ${ }^{14}$

In the present study, we used a single, mid-sagittal dorsal view, with the wrist joint in a neutral position and the hand flat onto the table, according to the Paediatric Group of the OMERACT US Task Force. ${ }^{8}$ However, instead of adding parasagittal views as suggested by the task force, we added a second mid-sagittal view in the flexed position to indirectly evaluate whether or not a visible recess might contain joint fluid. We appreciate

Table 3 Number of children with visible vessels in the vicinity of the RC and MC joints in 116 healthy children (59 girls) aged $6-16$ years, by age groups

\begin{tabular}{|c|c|c|c|c|c|c|c|}
\hline & $\begin{array}{l}6-7 \text { years } \\
(n=20)\end{array}$ & $\begin{array}{l}\text { 8-9years } \\
(n=23)\end{array}$ & $\begin{array}{l}10-11 \text { years } \\
(n=24)\end{array}$ & $\begin{array}{l}12-13 \text { years } \\
(n=18)\end{array}$ & $\begin{array}{l}\text { 14-16years } \\
(n=31)\end{array}$ & Total & $\begin{array}{l}\mathrm{P} \text { value } \\
\mathrm{X}^{2} \text { test }^{\star}\end{array}$ \\
\hline Within the radial epiphysis & 4 & 3 & 9 & 1 & 3 & $20(17.2 \%)$ & 0.287 \\
\hline Close to the $\mathrm{RC}$ joint & 0 & 3 & 2 & 3 & 3 & $11(9.5 \%)$ & 0.589 \\
\hline Close to the MC joint & 1 & 2 & 6 & 0 & 3 & $12(10.3 \%)$ & 0.888 \\
\hline
\end{tabular}

*Linear-by-linear association.

$\mathrm{MC}$, midcarpal; RC, radiocarpal. 
that the recesses most likely would decrease in thickness when stretched; however, the fact that some of them were no longer visible supports the presence of joint fluid. MRI-based studies on the wrist in healthy children support these findings. ${ }^{12}{ }^{15}$ Further quantification of the amount of joint fluid using US was considered unfeasible.

For the 0-2 scale used, intrareader kappa values for both the RC and MC recesses were good and very good, respectively. It is important to recognise that simple kappa values only take into account the presence or absence of absolute agreement and not the extent of disagreement. Opposite, the high variability of measurements of the thickness of both recesses, as demonstrated by wide $95 \%$ limit of agreement, indicates that these measurements are too imprecise for clinical use. This was not unexpected, as measuring small distances from images, be it US, radiography or MRI, typically perform poorly. ${ }^{16}$

Detailed analysis of our data revealed cases in which intraobserver variability was greatest. The largest discrepancies were identified in measuring the $\mathrm{MC}$ recess. This can in part be explained by difficulties in delineating the recess dorsally due to the variation in echogenicity of overlying soft tissues. In most children, this tissue, interposing the recess and the extensor tendons (figure 1), is relatively echogenic, whereas in some, it contains darker areas complicating the measurements. Furthermore, the cartilage covering the proximal end of the capitate, particularly if it extends slightly dorsally (figure 1), may mimic a recess, at least by less experienced examiners. In our experience, the anatomy around the $\mathrm{RC}$ recess was easier to appreciate, with a triangular, echogenic structure filling the notch between the radial epiphysis and the lunate (figure 1) being a constant finding. Imagewise, this structure most likely represents a fat pad, located between the bones and the overlying ligaments and tendons.

The presence of vessels in $8 \%$ of the RC and $4 \%$ of the $\mathrm{MC}$ recesses was surprising. One might argue that the vessels might be located in near proximity, rather than within the recesses. However, all unexpected findings were confirmed on additional axial scans. Indeed, in a recent paper by the Paediatric Group of the OMERACT US Task Force, aimed to describe the physiological vascularisation in four joints of children aged from 2 to 16 years, more vessels were seen in the wrist, using the longitudinal midline scan, than in any of the other joints. Although the number of healthy children was low, it is of note that vessels in the cartilage and adjacent fat pads of small bones were more commonly seen than epiphysial or growth plate vessels. Moreover, no vessels were seen within the joint recesses. Reasonably, this can be explained by the extremely low number of healthy subjects investigated, due to the purpose of the study. ${ }^{17}$

To our knowledge, this is the first study presenting normal US appearances of the wrist in children. Most of the cohort was recruited from one school in the city of Bergen, whereas 24 boys aged 12-16 years were recruited from one of the Bergen football clubs. However, we have no reason to believe that the dataset was biased as both the distribution of handedness and of participation in sport activities correspond well with figures reported for the general population. ${ }^{18}{ }^{19}$ Furthermore, none of the children reported on wrist pain or had joint swellings on clinical examination.

There are some limitations to our study. First, interreader variability was not assessed on site due to practical circumstances. Re-reading of all the images using a masked design, by the same observer, gave, however, good to very good agreement for scoring the recesses on a 0-2 scale. Second, although we used a state-of-the art transducer, higher frequency probes are now available. And last, detailed information on the use of cell phone and gaming was not available.

\section{CONCLUSION}

The US appearances of the dorsal RC and MC recesses in healthy children may mimic pathology. Hence, US findings in the wrist of children should be interpreted with care.

Contributors All authors contributed to the planning, reporting, discussion and final approval of the article. KR performed all the ultrasound examinations and drafted the first version of the manuscript.

Funding This research received no specific grant from any funding agency in the public, commercial or not-for-profit sectors.

Competing interests None declared.

Patient consent Obtained.

Ethics approval The Regional Ethics Committee (REK), HelseVest, Bergen, Norway. Provenance and peer review Not commissioned; externally peer reviewed.

Open Access This is an Open Access article distributed in accordance with the Creative Commons Attribution Non Commercial (CC BY-NC 4.0) license, which permits others to distribute, remix, adapt, build upon this work non-commercially, and license their derivative works on different terms, provided the original work is properly cited and the use is non-commercial. See: http://creativecommons.org/ licenses/by-nc/4.0/

(c) Article author(s) (or their employer(s) unless otherwise stated in the text of the article) 2018. All rights reserved. No commercial use is permitted unless otherwise expressly granted.

\section{REFERENCES}

1. Riise $\varnothing R$, Handeland KS, Cvancarova M, et al. Incidence and characteristics of arthritis in Norwegian children: a population-based study. Pediatrics 2008;121:e299-e306.

2. Ravelli A, Martini A. Juvenile idiopathic arthritis. Lancet 2007;369:767-78.

3. Smith MD. The normal synovium. Open Rheumatol J 2011;5:100-6.

4. Orr C, Vieira-Sousa E, Boyle DL, et al. Synovial tissue research: a state-of-the-art review. Nat Rev Rheumatol 2017;13:630.

5. Robben SG, Lequin MH, Diepstraten AF, et al. Anterior joint capsule of the normal hip and in children with transient synovitis: US study with anatomic and histologic correlation. Radiology 1999;210:499-507.

6. Rohrschneider WK, Fuchs G, Tröger J. Ultrasonographic evaluation of the anterior recess in the normal hip: a prospective study on 166 asymptomatic children. Pediatr Radiol 1996;26:629-34.

7. Trauzeddel R, Windschall D, Trauzeddel RF, et al. Arthrosonographic reference values of the shoulder joint in healthy children and adolescents: a cross-sectional multicentre ultrasound study. Klin Padiatr 2017;229:293-301.

8. Collado P, Vojinovic J, Nieto JC, et al. Toward standardized musculoskeletal ultrasound in pediatric rheumatology: normal agerelated ultrasound findings. Arthritis Care Res 2016;68:348-56. 
9. Roth J, Jousse-Joulin S, Magni-Manzoni S, et al. Definitions for the sonographic features of joints in healthy children. Arthritis Care Res 2015;67:136-42.

10. Collado P, Jousse-Joulin S, Alcalde M, et al. Is ultrasound a validated imaging tool for the diagnosis and management of synovitis in juvenile idiopathic arthritis? A systematic literature review. Arthritis Care Res 2012;64:n/a-1019.

11. Chauvin NA, Doria AS. Ultrasound imaging of synovial inflammation in juvenile idiopathic arthritis. Pediatr Radiol 2017;47:1160-70.

12. Müller LS, Avenarius D, Damasio B, et al. The paediatric wrist revisited: redefining MR findings in healthy children. Ann Rheum Dis 2011;70:605-10.

13. Collado P, Naredo E, Calvo C, et al. Assessment of the joint recesses and tendon sheaths in healthy children by high-resolution B-mode and power Doppler sonography. Clin Exp Rheumatol 2007;25:915-21.

14. Hiraga M, Ikeda K, Shigeta K, et al. Sonographic measurements of low-echoic synovial area in the dorsal aspect of metatarsophalangeal joints in healthy subjects. Mod Rheumatol 2015;25:386-92.

15. Avenarius DFM, Ording Müller LS, Rosendahl K. Joint Fluid, bone marrow edemalike changes, and ganglion cysts in the pediatric wrist: features that may mimic pathologic abnormalities-follow-up of a healthy cohort. AJR Am J Roentgenol 2017;208:1352-7.

16. Engesæter IØ, Laborie LB, Lehmann TG, et al. Radiological findings for hip dysplasia at skeletal maturity. Validation of digital and manual measurement techniques. Skeletal Radiol 2012;41:775-85.

17. Windschall D, Collado P, Vojinovic J, et al. Age-related vascularization and ossification of joints in children: an international pilot study to test multi-observer ultrasound reliability. Arthritis Care Res 2017.

18. Hardyck C, Petrinovich LF. Left-handedness. Psychol Bull 1977;84:385-404.

19. International Business Publications. Norway Country Study Guide. Washington CD, USA: International Business Publications, 2013. 